\title{
Cholera in Nineteenth-Century Europe: A Tool for Social and Economic Analysis
}

\section{Citation}

Rosenberg, Charles E. 1966. Cholera in nineteenth-century Europe: A tool for social and economic analysis. Comparative Studies in Society and History 8(4): 452-463.

\section{Published Version}

doi:10.1017/S0010417500004229

\section{Permanent link}

http://nrs.harvard.edu/urn-3:HUL.InstRepos:4730370

\section{Terms of Use}

This article was downloaded from Harvard University's DASH repository, and is made available under the terms and conditions applicable to Other Posted Material, as set forth at http:// nrs.harvard.edu/urn-3:HUL.InstRepos:dash.current.terms-of-use\#LAA

\section{Share Your Story}

The Harvard community has made this article openly available.

Please share how this access benefits you. Submit a story.

\section{Accessibility}




\section{CHOLERA IN NINETEENTH-CENTURY EUROPE:}

A TOOL FOR SOCIAL AND ECONOMIC ANALYSIS

Economists have, in the past generation, become deeply concerned with the problem of economic growth. Of late years, as traditional economic models have demonstrated inadequacies, economists have become increasingly interested in the social and cultural inputs necessary for growth in economic productivity. Human, value-related factors, particularly education, role definition, and the place of science and technology, have taken a place beside the more traditional categories of the economist and economic historian. ${ }^{1}$ But these human factors, important though all admit them to be, are, especially in historical contexts, not usually amenable to quantitative methods of datagathering. It is difficult, on the one hand, to evaluate and sample such elusive factors, and on the other hand to define their precise role in social change.

An epidemic disease, I suggest, provides an excellent sampling device for studying the numerous yet organically related factors which underlie increases in economic productivity. An epidemic, if sufficiently severe, necessarily evokes responses in every sector of society. A study of the responses to the same sharply focused and unavoidable stimulus should provide materials for the construction of a cross-section of cultural values and practices at one moment in time. Values and attitudes, especially in the areas of science, of religion, of traditionalism and innovation are, for example, inevitably displayed during an epidemic. Medicine itself is, of course, a social context, one in which science pure and science applied necessarily function together; the nature of their interaction during a crisis situation should provide clues to their ongoing relationship. Thus the behavior of society during an epidemic and of medicine as a social function provides an organic context in which the structural configuration of attitudinal and institutional factors may be discerned. This is, of course, not meant to imply that each of the factors mentioned could not be studied alone or by using other indices. An epidemic simply provides a convenient and effective sampling device for studying in their structural relationship some of the fundamental components of social change.

1 For a recent discussion of these trends in the context of econometric production models, see R. R. Nelson, "Aggregate Production Functions and Medium-Range Growth Projections", American Economic Review, LIV (1964), pp. 575-606. 
There is no human crisis more compelling than an epidemic of plague, or yellow fever, or cholera. These phenomena are, indeed, so dramatic and so terrifying that most physicians and historians have tended to view them as something alien, something outside of society and contending with it. ${ }^{2}$ This frame of reference has served well to dramatize the history of the great epidemic diseases and most discussions of the social and economic consequences of epidemic incidents have assumed this form. They attempt, that is, to demonstrate the direct impact of the disease upon the society attacked, either in terms of productivity curtailed or labor force reduced. (This is a position particularly congenial to physicians writing of the historical effects of disease, for it serves - seemingly - to demonstrate the importance of medical factors in history.) For more than a century, however, a variant approach, one which sees diseases as a function of social organization, has been available. Since at least the time of Virchow, physicians and historians of disease concerned with "social medicine", have tended to view disease, endemic as well as epidemic, not as an alien visitation, but rather as the consequence of social organization and especially of social inequity and social change. ${ }^{3}$

This strongly humanitarian and environmental approach has often placed little emphasis upon the individuality of disease entities. From this point of view, disease is essentially a pathognomonic sign, a symptom of underlying social pathology and the history of disease becomes a weapon for social criticism, not social analysis. Yet the individuality of disease is an indispensable aid in increasing the value of historical studies of epidemics. Differences in symptoms, for example, imply differing magnitudes of social response; differences in modes of transmission imply the ability to study different economic and ecological relationships. Influenza, for example, is not ordinarily studied by the social or economic historian; it is too easily transmitted, too universal - and insufficiently lethal or disfiguring. (Though its usual mildness, it should be noted, implies something of the values and capacities of a society which has undertaken to combat it.) At another extreme are the deficiency diseases in which the biochemical mechanisms underlying the clinical

2 One may compare these differences in approach to the two basic orientations which have always defined man's approach to disease. One sees disease as an invading entity, attacking the body from without, while the other views disease as a resultant of the sum of the individual's responses to certain patterns of stimuli. Cf. Owsei Temkin, "The Scientific Approach to Disease: Specific Entity and Individual Sickness", in A. C. Crombie, ed., Scientific Change, Historical Studies in the Intellectual, Social and Technical Conditions for Scientific Discovery and Technical Invention from Antiquity to the Present (London, Heinemann, 1963), pp. 629-647.

3 For a brief historical statement of the position of "social medicine", see George Rosen, "Approaches to Social Medicine. A Historical Survey", Milbank Memorial Fund, Backgrounds to Social Medicine (New York, Milbank Memorial Fund, 1949), pp. 9-23. For a discussion of Virchow's classic statement of this standpoint, see Erwin H. Ackerknecht, Rudolf Virchow (Madison, Wis., Univ. of Wisconsin Press, 1953), pp. 124-130 and the same author's Beiträge zur Geschichte der Medizinalreform von 1848 (Leipzig, J. A. Barth, 1932). 
manifestations are so specific that the presence of the disease is virtually a test for certain factors in the patient's environment. Most infectious diseases fall somewhere between these two extremes. Malaria and cholera, for example, are clearly, though complexly, related to stages of economic development. Malaria receded from large areas of the Western world before any knowledge of its mode of transmission was known. Screening, drainage of marshes, careful cultivation practices, an abundance of cattle - all products of economic development considered broadly - cumulatively interact to reduce the mosquito population and to decrease the chances of human beings being bitten. ${ }^{4}$ The correlation between economic growth and decrease in malaria seems, in general, to have been clearly established. The relationship, however, between economic growth and changing disease conditions is, because of the individuality of disease no simple one; measures which seem to imply increased productivity do not always bring a decreased incidence of infectious disease. Consider, for example, the cases in which the construction of irrigation and drainage canals for dry-land farming have actually increased the incidence of malaria and bilharziasis - an inevitable sequence when this specific artifact of economic growth comes into being in a society in which the evolution of medicine and public health have not organically paralleled this innovation. ${ }^{5}$ (Irrigation canals can provide, of course, excellent breeding places for the mosquitoes which transmit malaria or the snails which help transmit bilharziasis.) The proper approach to a study of malaria or cholera lies not in attempting to state with actuarial zeal their economic costs - but to allow their individuality as biological phenomena to help illumine the socio-economic features of the world in which they do, or do not, occur.

Cholera was the classic epidemic disease of the nineteenth-century, although — in all probability - it did not reach Europe until the 1830's. ${ }^{6}$ No

4 Erwin H. Ackerknecht has provided an excellent exposition of this interpretation of malaria: Malaria in the Upper Mississippi Valley 1760-1900 (Supplements to the Bulletin of the History of Medicine, No. 4) (Baltimore, The Johns Hopkins Univ. Press, 1945). 5 J. N. Lanoix, "Relation between Irrigation Engineering and Bilharziasis", Bulletin of the World Health Organization, XVIII (1958), pp. 1011-1035; Paul F. Russell, "Public Health Factors. Malaria and Bilharziasis", in L. Dudley Stamp, ed., A History of Land Use in Arid Regions (Paris, UNESCO, 1961), pp. 363-372.

B A recent and inclusive outline of cholera's history may be found in R. Pollitzer, Cholera (Geneva, World Health Organization, 1959), pp. 11-50. Still important are August Hirsch, Handbuch der historischgeographischen Pathologie, Bd. I: Die allgemeinen acuten Infektionskrankheiten (Stuttgart, 1881), pp. 278-348 and Georg Sticker, Abhandlung aus der Seuchengeschichte und Seuchenlehre, Bd. II: Die Cholera (Giessen, 1912). For an account of cholera in the United States, see Charles E. Rosenberg, The Cholera Years. The United States in 1832, 1849, and 1866 (Chicago, Univ. of Chicago Press, 1962). Charles Creighton's is still the best general history of cholera in England, though it has been superseded in its treatment of certain incidents. Creighton, A History of Epidemics in Britain. Vol. II (Cambridge, at the University Press, 1894), pp. 796-862. Roderick E. McGrew's Russia and the Cholera, 1823-1832 (Madison, Univ. of Wisconsin Press, 1965), which came to my attention after the paper was written contains a number of interesting parallels and incidents. 
disease of the nineteenth-century can be compared with it in terms of immediate emotional impact; cholera kills roughly half of those attacked and kills them, moreover, in a particularly unpleasant manner. And certainly cholera killed hundreds of thousands in each of its pandemic visitations to Europe. Yet it was indirectly, as a catalyst in the development of the public health movement, that cholera played its essential role in affecting European economic and demographic patterns. That is, it is not the men actually dying of cholera who are significant, but rather those who did not die because of the public health measures instituted in fear of the disease. It is impossible, so far as I know, to discover in the literature a single instance in which urban growth or a pattern of local economic development was lastingly influenced by the immediate mortality from cholera. ${ }^{7}$ Though the disease did play a central role in crystallizing sentiment in favor of public health and environmental reform, it could only have done so in a society in which the appropriate attitudinal, economic, and technological means were at hand.

When cholera arrived in Western Europe in 1831-32, it was subjected to the scrutiny of a rapidly maturing scientific community. In the 1830's the disease was a mystery; by the 1860 's, however, the medical profession - or at least its more advanced members - possessed a workable empirical knowledge of its mode of transmission. In 1883, Koch discovered the specific causative organism and Western Europe's last significant brush with cholera took place in the 1890's. (Though certain areas, as the British Isles, never allowed the disease a substantial foothold after the 1870's.) A study of Europe's initial encounter with cholera demonstrates the existence of a relationship already well-defined between science, medicine, and social values; its visitations later in the century - for cholera was never endemic in Europe demonstrate with equal clarity the rapid development of this society in a parallel and inter-related pattern of economic, technological, scientific, and institutional growth.

Before the 1830's, cholera had been seen only by physicians in India; as it moved West, however, in the late 1820's it attracted increasing interest. As soon as the disease appeared in Russia, in Poland, and in Germany, medical commissions from England and France were appointed to report on this seemingly new and certainly appalling disease. Not surprisingly, however, considering their inadequate etiological knowledge, the explanations of these

7 Morbidity statistics in the 1830 's, even in the larger cities, were reported and recorded in a somewhat tenuous fashion, partially as a reflection of the formlessness of most physician's diagnoses. For an example of the difficulty of determining even so relatively uncomplicated a fact as comparative class and occupational death rates from cholera, see Louis Chevalier, Le Choléra. La Première Épidémie du XIXe Siècle (Bibliothèque de la Révolution de 1848, Tome XX) (La Roche, Imprimerie Centrale de L'Ouest, 1958), pp. 1-45. Chevalier's demographic study of Paris during the 1832 cholera epidemic - a study, it should be noted, based on atypically full records - represents what is probably the most complete study of any community during this epidemic. 
medical commissioners and those of their contemporaries were based as much upon moralism as empirical analysis. And, indeed, the twentieth-century observer will be struck not only with the moralistic elements in the hypothetical etiologies of medical thought; but equally by the orthodox religious interpretations of the epidemic so prevalent thoughout Western Europe and the United States, both in Catholic and Protestant areas. The individual who succumbed to cholera, both physicians and ministers agreed, had predisposed himself to disease, had somehow weakened his constitution. And the means by which one could accomplish this were as varied as the occasions of sin. Drinking, overeating, sexual excess, for example, might all dissipate one's vital forces and thus leave one defenseless against the cholera-causing principle in the atmosphere. Ministers and moralists in general, moreover, tended to see and interpret the epidemic not as a consequence of individual transgression alone, but as the result of a national failing in morality. In a sense, however, the significance of these traditional supernaturalistic interpretations lies not in their pervasiveness, but in the manner in which such thought had been segregated; it was no longer a dominant sphere of values, but a domain supplementary and alternative to that of science and empirical knowledge. It is impossible to find instances in the 1830's in which theological imperatives clearly impaired the autonomy of medical thought. Both ministers and physicians accepted the emotional relevance of both reference areas. Thus the ingenuity with which clergymen explained the moral lessons of cholera in terms of physiological mechanisms, while the physician with equal facility expressed in his etiological theory the accepted moral teachings of his generation. That cholera had been sent by the Lord in punishment of sins individual and collective did not imply the impossibility, the impiety, or even the undesirability of attempting to explain and prevent the disease. ${ }^{8}$ Indeed both theologians and physicians agreed that it was men's duty to employ God's temporal means to preserve human life; prayer could not be expected to prevail if man did not alter the second causes through which cholera acted. No amount of prayer would clean filthy streets and tenements. One could not expect miracles in the nineteenth-century. Growing secularism paralleled scientific progress and by the 1860 's, the theological and moralistic explanations of the disease so prominent in the 1830's had, with increasing medical knowledge, become a clearly marginal theme.

The relative autonomy of medical and scientific values characterized a community of medical thought and practice in some ways surprisingly mature. In pathology, in therapeutics, even in public health practice, intimations of cholera's ultimate conquest were already apparent in the early 1830's. More enlightened physicians in Europe and North America had already come to

8 Rosenberg, Cholera Years, pp. 40-54, 121-132, and passim. Though the preceding reference is based on American sources, subsequent research has indicated that these conclusions hold true, on the whole, for England and the Continent. 
accept pathological anatomy as a necessity in the understanding and defining of disease entities. (And, indeed, the first general acceptance in medical circles of the idea that diseases were specific, discrete entities is connected with this period and this approach.) As soon as cholera reached Russia and as it moved West, pathologists began to study the physical changes which it wrought in its victims. A number of physicians, for example, made detailed examinations of the stomach and intestinal linings and contents of cholera victims. Such studies, of course, could not prevent the disease, nor were they pursued by more than a small minority of physicians. Yet one cannot deny the sophistication of a community which produced such patient studies and had nurtured a flourishing clinical school, one which emphasized the correlation of disease symptoms in life with pathological findings after death.

Let me suggest another, and I think particularly striking, illustration of the relative maturity of Western medicine in the 1830's. It is an incident, moreover, which suggests the relationship already subsisting between scientific progress and change in medical practice, and as well the willingness of at least some members of the medical profession to innovate and experiment with any technique promising socially meaningful results. When cholera first appeared in Europe, a centuries-old-tradition had already created an interest in pathological changes in the blood of the sick; in the early nineteenth-century, however, this traditional interest in humoral pathology had been given a new impetus and content by the application of knowledge originating in experimental chemistry. It was inevitable that a number of physicians, attracted by the alluring certainties of the new chemistry, would study the chemical and physical changes in the blood of cholera victims. It was soon announced that the blood of patients succumbing to cholera exhibited drastic physical and chemical changes. The proportion of serum to solids was clearly reduced, while the acidity of the blood seemed to have altered as well. (Though there was disagreement among the several investigators publishing on the subject as to the precise nature of these chemical alterations.) All the symptoms of cholera, the argument followed, proceeded from these hematological changes and, logically enough, it was concluded that patients might be cured by injecting saline solutions into their veins and thus restoring the blood to its proper chemical and physical make-up. ${ }^{9}$ And indeed this technique was experimented with relatively widely by physicians willing to look anywhere

9 There is no detailed modern study of this incident. For useful summaries, however, see Pollitzer, Cholera, pp. 611-615; A. B. Garrod, On the Pathological Condition of the Blood in Cholera (London, Richards, 1849), pp. 2-11, 29. Garrod's summary is particularly useful as it embodies the author's already more critical view of the rough-andready methods and conclusions of the medical chemists of the 1830's. The English discussion of saline injection and its rationale may be followed in the London Lancet and London Medical Gazette for 1832; for parallel work done in Russia, see R. Hermann, Analyses chimiques: contenant l'exposé des altérations qui subissent le sang et les sécrétions du corps humain pendant le choléra (Moscou, 1832). 
for help in treating cholera - or at least to any source bearing the imprimatur of science.10 These pathological conclusions and the therapeutic measures deduced from them did not actually succeed in curing patients; their technique was neither sterile nor otherwise appropriate and was tried only on patients in extremis. This incident demonstrates clearly, however, the conjunction of a number of different factors. One, for example, is the manner in which science had already begun to become part of medicine and to some physicians at least an indispensable part - and how in a crisis situation, at least some physicians turned naturally to investigation and to experimentation. This incident illustrates as well the ease with which information was diffused within the European medical community - including its provincial outposts in the western hemisphere. Within the space of less than a year, experiments with saline injection were tried from Russia in the East to North America in the West. Even though the international community of medicine was limited to the better-educated, more critical, often urban physicians, its presence and integrity cannot be denied. One might well argue on the basis of such instances that a scientific and technological "take-off" stage had already been attained by the early 1830 's. Certainly it would seem to indicate a stage which non-Western countries have been unable or unwilling to reach without an input of intellectual and economic capital from without their own society. Thus the difference between cholera - or malaria - in India and in the West. Means were clearly evolving within Western society which would ultimately limit such ills, while nations not participating in the West's economic, technological, scientific, institutional, and attitudinal development have not organically developed within their own societies the means to banish these pestilences.

The manner in which cholera dramatized and justified existing demands for public health and municipal reform could only have taken place in a society in which the possibility of meliorism seemed plausible and the attempt to achieve it an imperative in at least some minds. Obviously a complex set of attitudes and influences conditioned European and American responses to cholera; humanitarianism, evangelical religion, utilitarianism, and so forth. Central to all, however, was a faith in means and in the assumption that a mixture of social organization and scientific inquiry would inevitably provide a means of vanquishing cholera.

10 For an enlightening contrast between the appeal which novelty, if clothed in the prestige and style of science makes to the Western mind, and the place of supernatural values in the mind of a Chinese village during a cholera epidemic, see Francis L. K. Hsu, Religion, Science and Human Crises (London, Routledge \& Kegan Paul, 1952). Equally relevant to the same consideration is the somewhat undignified struggle for priority in the discovery and popularization of this new mode of therapy. (See, for example, Thomas Craigie's, Statement of Facts with Observations, Edinburgh, 1832.) It is important to remember that many physicians were already quite conscious of their place in an international structure of knowledge and status. 
It is these attitudes which are significant, though the specific medical theories which justified public health measures were in detail wrong. The idea, for example, that the availability of an adequate supply of pure water might prevent cholera is one which we find it natural to accept. Publicspirited physicians and reformers generally supported the idea in the 1830's that water was necessary primarily to keep the streets clean and thus prevent the accumulation of miasma-breeding filth. (Almost all physicians at the time assumed that the presence in the atmosphere of deleterious miasmatic substances played an essential role in the causation of the disease, either through debilitating the individual or by acting as a specific causative factor.) Water should be not only abundant, but pure, not because some "virus" might be spread through it, but because the consumption of contaminated water would weaken the body's natural power of resistance and thus predispose it to disease. The important thing is not the accuracy or inaccuracy of the particular formulation, but the concern for environmental factors which these ideas implied and as well the parallel conviction that something should be if something could be - done to change living conditions which seemed to breed cholera as well as other infectious ills.

Most dramatically, an explanation of cholera was made available in midnineteenth-century, an explanation which provided not only some understanding of the etiology of the disease, but implied as well the creation of effectual preventive measures. John Snow, a London physician, suggested as early as 1849 that cholera was a contagious disease caused by a poison reproducing itself in the bodies of its victims. The poison was to be found in the excreta and vomitus of cholera patients and, according to Snow, it was these substances that spread the disease, most frequently through a contaminated water supply.

From the point of view of this discussion, we must consider Snow's argument as an artifact peculiar to the generation which produced it; like other cultural artifacts, it incorporated diverse yet characteristic elements. ${ }^{11}$ Even a generation previously, Snow's reasoning would have been improbable, if not impossible. His argument subsumed advances in chemistry, in pathology, in technology, and in public health practice. Snow's first logical step was the assumption, based on certain pathological findings of the first epidemic, that changes in the stomach and intestines indicated that the alimentary canal was the true seat of the disease and that changes in the blood and other organs

11 William Farr, another pioneer English epidemiologist, came to very similar conclusions at almost the same time. For the sake of convenience, however, I shall refer in succeeding passages to these new ideas as "Snow's", though he was not alone in holding thern. Snow's major publications have been reprinted by the Commonwealth Fund, with an introduction by Wade Hampton Frost (Snow on Cholera, New York, The Commonwealth Fund, 1936). The best brief discussion of Snow's work, though perhaps overly anti-heroic, is P. E. Brown's, "John Snow - The Autumn Loiterer", Bulletin of the History of Medicine, XXV (1961), pp. 519-528. 
were epiphenomenal in nature. Thus it seemed likely, Snow submitted, that the disease-causing substance was taken into the body by way of the mouth and considering contemporary personal and public hygiene it was not difficult to suggest the channels by which this substance might find its way from one alimentary tract to the next. Nor did the ability of this hypothetical substance to reproduce itself (or to induce continuous molecular change as Snow put it) seem unlikely. The fermentation controversy had been raging for several generations and in Snow's day the issue was an urgent one. But whether one accepted the biological or the chemical explanation of fermentation, it required little imagination to find in the process itself an analogy by means of which epidemic disease might be explained. It required, that is, little imagination to visualize a disease-causing microscopic substance which might act as a ferment, reproduce itself continuously and in doing so bring about changes in the surrounding medium. Scientific experience with inoculation and vaccination had also shown the ability of minute quantities of morbid material to reproduce themselves in the human body and thus cause disease. (Similar conclusions followed from experiments in the transmission of syphilis.) ${ }^{12}$ It had, moreover, been shown conclusively by the 1840's that fungi could cause disease in man, in plants, and in insects. It was only to be expected that simultaneously with Snow's early publications on cholera, other investigators were announcing that they had found microscopic fungi in the excreta of cholera patients, fungi which they argued were the cause of the disease. ${ }^{13}$

Snow's epidemiological reasoning is equally revealing. His original pamphlet, published in 1849 , caused no immediate stir. It was one among dozens of hopeful theories published at the time. Anyone could, and many did, compose a fanciful etiology of cholera; the problem was to prove it. Snow, unlike the others, did. Most striking is his demonstration that cholera was spread through a contaminated well by tracing individual cases to use of water from the suspected pump. Equally striking is Snow's use of the Registrar-General's records to show a difference in the cholera case rate between customers of one London water company which drew its water from the Thames above the point at which it would be contaminated with London sewage with another

12 Snow on Cholera, pp. 156-157.

13 These investigators were, not surprisingly, wrong in their identification of particular fungi. But their interest is symbolic of a steadily increasing interest in the study of microscopic phenomena. A recent reviewer, for example, accepts the claims of at least four different investigators as having actually seen the cholera vibrio by 1867 - that is sixteen years before Koch's discovery. S.N. De, Cholera. Its Pathology and Pathogenesis (Edinburgh, Oliver \& Boyd, 1961), pp. 14-15.

14 Snow found that - despite the help of the Registrar-General's Office - it was in many cases difficult to discover which of the two companies had serviced particular houses. Significantly, Snow also tested the actual water with a silver nitrate solution, finding that the sewage polluted water of the Southwark \& Vauxhall Company had a much higher sodium chloride content than that of the Lambeth Company's water. Snow on Cholera, pp. 77-78. 
company which drew its supply from below that point. ${ }^{14}$ Just as Snow's ability to posit an appropriate etiological agent was a product of changes both scientific and technological, so equally was his epidemiological reasoning a product of the multiple aspects of change which had taken place in the first half of the nineteenth-century. Indeed both water companies and the Registrar General's office itself were created in this period. It would be hard to imagine a mideighteenth-century student of epidemic disease determining individual cases and then plotting them on street maps. By mid-nineteenth-century, Snow was only one among a number of physicians who carefully mapped individual cholera cases in recording and analyzing the history of local epidemics. ${ }^{15}$ Snow's attitudes were in general characteristics of the scientism and utilitarianism which he shared with so many of the scientific leaders of his generation. Rationalistic and "imponderable" considerations he simply dismissed. The problem of predisposition to disease, a concern of physicians since Hippocrates, he casually rejected as a hypothesis required by ignorance alone. ("The alleged predisposition", Snow caustically remarked, "was nothing visible or evident: like the elephant, which supports the world, according to Hindoo mythology, it was merely invented to remove a difficulty." The difficulty, of course, being the immunity of some to epidemic influences supposedly in the atmosphere though all were equally immersed in this same atmosphere. ${ }^{16}$ If Snow's reductionism has a narrow and perhaps even ruthless tinge, it is a characteristically modern ruthlessness. Cholera could not have been understood in 1832. Yet the conditions that nurtured and spread cholera already did exist. An urban and industrial society had come into being, a society with comparatively rapid and frequent modes of transportation; for a brief period cholera could thrive in this material culture, but only for the relatively short period during which the same processes of change which created this material culture produced as well the medical and administrative advances which would inevitably banish the disease.

15 E. W. Gilbert ("Pioneer Maps of Health and Disease in England", Geographical Journal, CXXIV (1958), 172-183) has emphasized the role of cholera in first stimulating the application of cartography to problems of epidemiology. For examples of such mapping by contemporaries, see Henry Acland, Memoir on the Cholera at Oxford in the Year 1854, with considerations suggested by the epidemic (London, 1856) and Thomas Shapter, The History of the Cholera in Exeter (London and Exeter, 1849). It should be noted, however, that mapping cases did not guarantee one's accepting some theory of infection or contagion. The often erratic pattern of distribution of cholera cases frequently seemed to preclude contagion. Lloyd G. Stevenson in a recent article has argued that the first use of spot maps came in the discussion of yellow fever in the 1790's and in the first decades of the nineteenth century ("Putting Disease on the Map: The Early Use of Spot Maps in the Study of Yellow Fever", Journal of the History of Medicine, XX (1965), pp. 226-261). It seems clear, however, that the first general use of such maps came in the study of cholera; certainly their general use by mid-nineteenth century would indicate an increasingly pervasive empiricism in temper.

16 Snow on Cholera, p. 159. Compare Snow's equally casual dismissal of the problem of vitalism, ibid., p. 146. 
Needless to say, Snow's ideas and those of his like-thinking colleagues did not meet with immediate and universal approval. ${ }^{17}$ But by the mid-1860's, when cholera next appeared in Western Europe, his studies of the mid-1850's had already won many converts. In the 1860's sporadically and in the 1870's more generally public health authorities were putting into execution the admonitions of medical spokesmen who felt with Snow that the disease was spread from person to person by some microscopic living organism. ${ }^{18}$ (This, of course, before Koch's discovery of the cholera vibrio in 1883.) After the 1870's, Western Europe and North America were spared wide-spread and devastating epidemics of the kind which had been so destructive earlier in the century.

To apply Snow's prophylactic conclusions, moreover, changes would have to be made in the evolving pattern of municipal government. (And, of course, as an instance of feedback, the existence of these new medical concepts and the necessity of implementing them provided at once the occasion and the justification for such increases in municipal power.) Let us outline in this connection another and final illustrative example. The United States in 1866 was in terms of world science at best provincial, in terms of municipal administration chaotic. In 1866, however, public-spirited New Yorkers made the threat of cholera an occasion for successful agitation for the creation of a board of health with powers appropriate to its task. ${ }^{19}$ And, as the New York medical profession generally accepted Snow's conclusions, it was the newer ideas which defined the appropriateness of the Board's powers. Men and means had to be provided if clothing and infection, for example, was central. Even before the first case of cholera in New York, the city's new board of health procured a building for the storage of chemicals to be used in disinfection of the excreta and personal effects of cholera victims. A number of wagons were purchased; and these, together with a sufficient complement of horses, were kept in a stable close by. Also quartered nearby and in constant readiness were details of men especially trained in the use of disinfectants. When the first cases appeared, each was reported at the closest police precinct station. The victim's address was immediately telegraphed to the Board's central of-

17 For a discussion of the reaction to Snow's ideas, see Rosenberg, Cholera Years, pp. 196-200. Particularly striking was the example of John Simon, the great organizer of English public health; despite what would seem to be his detailed and overwhelmingly elaborate proof of Snow's contention that cholera was essentially a water-borne disease, Simon himself could, in the 1850 's, consider contaminated water to be only one among several possible causes of the disease. Royston Lambert, Sir John Simon 1816-1904 and English Social Administration (London, Macgibbon \& Kee, 1963), pp. 247-249.

18 Particularly illuminating is the United States Government's report on The Cholera Epidemic of 1873 in the United States; this report shows in exhaustive detail the general acceptance of these new ideas even in small, semi-rural communities (Executive Doc. No. 95, 43rd Cong., 2nd sess., Washington, Government Printing Office 1875).

19 The most detailed account of the Metropolitan Board of Health's fight against cholera in 1866 is to be found in its first annual report (New York State, Annual Report of the Metropolitan Board of Health, 1866, New York, 1867). 
fice, which quickly dispatched a wagon-load of disinfectants to the infected premises. Within an hour of the report's having been made, a detail of welltrained men would be at work disinfecting the clothing, house and effects of the victim.

This particular example need not be pursued too far; its meaning seems clear enough. The chemicals, the telegraph, the efficiency and care of organization were, like Snow's ideas themselves characteristic products of the material development of Western society. If, in 1831, when cholera first appeared in the West, we could discern the formative elements in the development of modern technological society - the close relation between science pure and science applied as seen in medicine, the autonomy of scientific and economic motives, the faith in meliorism and the assumption of the necessity and meaningfulness of human actions - we can see by the 1860's a far more mature stage in the development of this society. In each case, however, epidemics of cholera provide a cross-sectional phenomenon in terms of which the structural relationships of these aspects of change may be studied.

CHARLES E. ROSENBERG

University of Pennsylvania 